\title{
SARS-CoV-2 will continue to circulate in the human population: no worries with state-of-the-art research and dependably useful results
}

\author{
Volodymyr V. Oberemok $^{1} \cdot$ Kateryna V. Laikova ${ }^{1} \cdot$ Kseniya A. Yurchenko ${ }^{1} \cdot$ Irina I. Fomochkina ${ }^{1}$. \\ Anatolii V. Kubyshkin ${ }^{1}$
}

Received: 7 October 2020 / Revised: 14 October 2020 / Accepted: 20 October 2020 / Published online: 30 October 2020

(c) Springer Nature Switzerland AG 2020

\begin{abstract}
This short article provides additional justification for our understanding of the virus-host relationship in the population. Some new data are presented concerning viral structure/behavior and a critical assessment on the possibilities of using new approaches for the treatment of patients with COVID-19.
\end{abstract}

We have carefully analyzed the article "Don't Worry! The Next Generation Would be More Resistant to SARS-CoV-2" written by Joseph J Bevelacqua and SMJ Mortazavi [1]. Unfortunately, the authors did not read thoroughly enough the article "SARS-CoV-2 will continue to circulate in the human population: an opinion from the point of view of the virus- host relationship" by Oberemok V. et al. [2] and have drawn the wrong conclusions that are more like assertions than critical analysis.

Almost all speculations of J Bevelacqua and SMJ Mortazavi are based on their statement that "Oberemok V. et al. only focus on the natural selection of humans and ignore the key point that, at least in the case of widespread use of vaccines and antiviral drugs, natural selection of the SARS$\mathrm{CoV}-2$ will also drive the virus to more mutations through an evolutionary process".

In many ways, the answers to this question were in the article because Oberemok V. et al. wrote "It must be understood that the short-term relationship between the virus and the host is always the result of Darwin's microevolution. Individuals who do not die in the fight against the virus will form a generation that is more resistant to the virus over time. The virus will continue to reproduce in these individuals, but will not pose a great danger to them. On the

Responsible Editor: John Di Battista.

Anatolii V. Kubyshkin

Kubyshkin_av@mail.ru

1 V.I. Vernadsky Crimean Federal University, Simferopol, Russian Federation other hand, humanity is capable of inventing drugs against viruses and slowing down the progress of Darwin's microevolution, saving the lives of those who otherwise might die without treatment". In addition, "Humanity will definitely survive. Drugs and vaccines will save the lives of some virus-sensitive people. Deaths among people of reproductive age will gradually lead to a human population in which the next generations will be more resistant to this virus". More conclusions on this issue can be found in a recent article of Oberemok V. et al. (2020) "SARS-CoV-2 will constantly sweep its tracks: a vaccine containing CpG motifs in 'lasso' for the multi-faced virus" [3].

In addition, criticizing the vision of the relationship between the virus and the host presented in the article, the authors refer to a number of publications that allegedly refute the given data. In particular, the article by K. Kupferschmidt "The pandemic virus is slowly mutating. But is it getting more dangerous?" in Science [4]. The article [Science. 2020 Jul 17;369(6501):238-239] in fact discusses the rare and totally random mutations of the SARS-CoV-2 virus, in particular the D614 to G614 mutant (single nucleotide change) in the spike protein, which is relatively innocuous. That is, the author is discussing the notion of viral resistance. The statement "that could change with the advent of vaccines or new therapies, forcing the virus to evolve" is only an unsubstantiated assumption by the author.

In addition, in our opinion, the last phrase "Other approaches including low dose radiation therapy offer significant advantages over antiviral agents, and should receive careful consideration as a treatment option" looks completely illogical and unproven in this publication. Low 
doses of radiation therapy (LDRT) may be considered as a possible approach in the complex treatment of inflammatory diseases, but this method is far from being used due to an insufficient evidence base. In particular, the possibility of a large number of negative side effects is indicated in the publication [5], which demonstrates its contraindication for the treatment of patients with COVID pneumonia. We also agree with Amirhosein Kefayat and Fatemeh Ghahremani [6] that "The LDRT is currently used for the decrease of limited inflammations in particular diseases like osteoarthritis and not a cytokine storm. Thus, the anti-inflammatory effect of LDRT may not be very effective in controlling this storm in COVID-19". These authors also rightly noted that "A comprehensive review of literature exhibited that all the publications about LDRT for pneumonia treatment are too old and have not been established with satisfactory scientific reliability. Also, considerable limitations and defects in the animal experiments of these publications were observed". Moreover, there is also limited knowledge about the interaction of LDRT and viruses. Some studies indicate substantial activation of different viruses after radiation therapy [7,8]. Thus, there are too many questions to be answered to be confident in the safe use of LDRT against COVID-19.

Of note, scientists may have different points of view on different problems and we invite Drs. Bevelacqua and Mortazavi to write their own opinion on how SARS-COV-2 might evolve.

Funding This work was supported by state program No FZEG-20200060 of the Russian Federation.

\section{References}

1. Bevelacqua JJ, Mortazavi SMJ. Do not worry! The next generation would be more resistant to SARS-CoV-2. Inflamm Res. 2020;1:13. https://doi.org/10.1007/s00011-020-01405-2.

2. Oberemok VV, Laikova KV, Yurchenko KA, Fomochkina II, Kubyshkin AV. SARS-CoV-2 will continue to circulate in the human population: an opinion from the point of view of the virushost relationship. Inflamm Res. 2020;69(7):635-40. https://doi. org/10.1007/s00011-020-01352-y.

3. Oberemok VV, Laikova KV, Yurchenko KA, Marochkin NA, Fomochkina II, Kubyshkin AV. SARS-CoV-2 will constantly sweep its tracks: a vaccine containing CpG motifs in 'lasso' for the multi-faced virus. Inflamm Res. 2020;69(9):801-12. https:// doi.org/10.1007/s00011-020-01377-3.

4. Kupferschmidt $\mathrm{K}$. The pandemic virus is slowly mutating but is it getting more dangerous. Science. 2020;369(6501):238-9. https ://doi.org/10.1126/science.abd8226.

5. Kirsch DG, Diehn M, Cucinotta FA, Weichselbaum R. Lack of supporting data make the risks of a clinical trial of radiation therapy as a treatment for COVID-19 pneumonia unacceptable. Radiother Oncol. 2020;147:217-20. https://doi.org/10.1016/j. radonc.2020.04.060.

6. Kefayat A, Ghahremani F. Low dose radiation therapy for COVID-19 pneumonia: a double-edged sword. Radiother Oncol. 2020;147:226. https://doi.org/10.1016/j.radonc.2020.04.026.

7. Iordanskiy S. Therapeutic doses of irradiation activate viral transcription and induce apoptosis in HIV-1 infected cells. Virology. 2015;485:1-15. https://doi.org/10.1016/j.virol.2015.06.021.

8. Ramirez-Fort MK. Radiotherapy-induced reactivation of neurotrophic human herpes viruses: overview and management. J Clin Virol. 2018;98:18-27. https://doi.org/10.1016/j.jcv.2017.11.004.

Publisher's Note Springer Nature remains neutral with regard to jurisdictional claims in published maps and institutional affiliations. 